\title{
MicroRNA array and microarray evaluation of endometrial receptivity in patients with high serum progesterone levels on the day of hCG administration
}

\author{
Rong Li', Jie Qiao ${ }^{1 *}$, Lina Wang ${ }^{1}, \mathrm{Li} \mathrm{Li}^{1}$, Xiumei Zhen ${ }^{1}$, Ping Liu' ${ }^{1}$ Xiaoying Zheng ${ }^{2}$
}

\begin{abstract}
Background: To determine the effect of higher progesterone (P) level on endometrial receptivity.

Methods: This was a prospective analysis conducted in the Reproductive Medical Center of Peking University Third Hospital. All patients received IVF treatment and canceled embryo transfer in the same cycle and were divided into group 1 (normal P; 7 patients) and group 2 (elevated P; 12 patients). Endometrial biopsies were performed 6 days after oocyte retrieval. The global miRNA and mRNA gene expressions in endometrial biopsies were investigated with a V4.0 miRNA probe and $22 \mathrm{~K}$ Human Genome Array. Fold ratios were derived to compare gene regulation between the groups. Spp1 and Ang gene expression was selected to verify the array results by RT-PCR and the protein expression of osteopontin and VEGF was determined using an immunohistochemical method.

Results: There were 4 miRNA (all down-regulated) and 22 mRNA (13 up-regulated and 9 down-regulated) exhibiting differential expression between the groups on the microRNA and microarray chips. miRNA-451, Spp1, and Ang expression in RT-PCR verified the array results. Osteopontin and VEGF were also shown to have positive expression in the endometrium.

Conclusions: Data from microRNA and microarray analysis suggests dissimilar endometrial receptivity in patients with high P levels on the day of hCG, and elevated osteopontin and decreased VEGF had poor pregnancy rates.
\end{abstract}

\section{Background}

Elevated serum progesterone (P) on the day of human chorionic gonadotrophin (hCG) has been reported to occur in $20 \%-40 \%$ of in vitro fertilization (IVF) and embryo transfer (ET) cycles [1]. Our clinical research has shown the pregnancy outcome was much poorer (13.79 versus $44.68 \%$ ) if the serum $P$ on the day of hCG was $>6.0$ $\mathrm{nmol} / \mathrm{l}$. However, the potential effect of these subtle increases on implantation remains controversial. Some argue that high serum $\mathrm{P}$ concentrations could have an adverse effect on oocyte quality or endometrial conditions [2]. Recent clinical studies have supported this notion of decreased endometrial receptivity. Melo et al. [3]

\footnotetext{
* Correspondence: jie.qiao@263.net

'Peking University Third Hospital, No. 49, North Huayuan Road, Haidian District, Beijing 100191, PR China

Full list of author information is available at the end of the article
}

conducted experiments involving patients in oocyte donation cycles (two cycles per woman, one normal and another $\mathrm{P}$ elevation cycle). The recipient's pregnancy rates were similar per IVF-ET, whether or not P was elevated. Our clinical research also showed that patients with elevated P had a poor outcome of fresh ET cycles, but a similar successful outcome in frozen embryo transfer (FET) cycles compared with the normal P group [4]. These reports further confirmed the link between poor pregnancy rates and decreased endometrial receptivity in patients with elevated $\mathrm{P}$, not fertilization or embryo quality.

Endometrial receptivity is a complex process, both temporally and spatially restricted. Improved endometrial receptivity and embryo preparation should lead to increased pregnancy rates and reduced early pregnancy failure [5]. It is generally assumed that the receptive
Ciomed Central

() 2011 Li et al; licensee BioMed Central Ltd. This is an Open Access article distributed under the terms of the Creative Commons Attribution License (http://creativecommons.org/licenses/by/2.0), which permits unrestricted use, distribution, and reproduction in any medium, provided the original work is properly cited. 
window of the human menstrual cycle is limited to days 19-24 [6], and days 8-10 post-ovulation [7]. Endometrial receptivity has been extensively studied, with a number of biochemical markers for endometrial receptivity having been proposed [8], including integrin and leukaemia inhibitory factor (LIF), although none of the biomarkers has proven to be clinically useful as an indicator [9]. In fact, many factors can play roles in endometrial receptivity, making it difficult to gain a clear understanding of gene regulation in the endometrium [10]. Are there any such uterine markers of endometrial receptivity associated with higher P levels?

During the past few years, both complementary DNA (cDNA) and oligonucleotide microarray technologies have been successfully applied to the study of endometrial gene expression [11]. The availability of this technology makes it possible to investigate the endometrial receptivity process from a global genomic perspective [12]. miRNAs are small (approximately $22 \mathrm{nt}$ ) ribonucleotides found in both animal and plant cells which play important roles in cellular differentiation, tissue development, and apoptosis by regulating gene expression and protein translation. Therefore, the current investigation sought to identify miRNAa- and mRNAs associated with the development of endometrial receptivity by comparing global gene expression patterns in normal and elevated $\mathrm{P}$ endometrium. Characterization of the complex relationship between miRNAs and the target mRNAs in endometrial receptivity may assist in the determination of the molecular pathways that affect receptivity; however, that cannot be completely elucidated by mRNA gene expression analysis alone. Both miRNA array and microarray were employed to detect the main factor acting upon the poor receptivity of patients with elevated $P$.

\section{Methods}

\section{Patient details and tissue collection}

All participants, 25-36 years of age, underwent transvaginal ultrasound and physical examination; none had positive findings. The patients all had tubal or male factor infertility. Endocrinopathies, organic diseases, and other factors affecting endometrial receptivity, such as polycystic ovary syndrome (PCOS), ovarian tumor, polyps, fibroids, endometriosis, and hydrosalpinx were excluded. All patients underwent IVF-ET with gonadotrophinreleasing hormone agonist ( $\mathrm{GnRHa}$ ) and recombinant FSH ( $\mathrm{rFSH})$. A total of 19 endometrial samples were collected in this study and separated into 2 groups. The mean ages in normal and elevated $P$ groups were 29.63 and 32.07 years, respectively $(P>0.05)$. Group 1 consisted of patients with normal $P$ levels (serum P levels $<4.0 \mathrm{nmol} / \mathrm{L}$ on the day of hCG) and included 7 patients who had opted out of ET in order to avoid ovarian hyperstimulation syndrome (OHSS) in IVF-ET cycles. Group 2 consisted of patients with elevated P levels (serum P levels $>6.0 \mathrm{nmol} / \mathrm{L}$ on the day of hCG, which was defined by our clinical research [4]), including 12 patients who had cancelled fresh ET in hopes of improving the chances for success during frozen ET cycles. Endometrial tissue biopsies were performed by dilation and curettage 6 days after oocyte retrieval. Each endometrial sample was further divided for the following studies: one portion was used for routine histologic processing and immunohistochemistry (IHC) in paraffin blocks to assess Noyes staging; the remainder was immersed in RNA Later solution and stored at $-80^{\circ} \mathrm{C}$ until RNA extraction. Ten samples (5 per group) were evaluated for the expression of miRNAs and mRNAs.

Informed consent was obtained for all patients undergoing endometrial biopsies; these protocols were approved by the Ethics Committee of Peking University Third Hospital.

\section{miRNA isolation labeling and microcrarry analysis}

Five endometrial samples from patients in each group were used for microarray hybridization according to the manufacturer's instructions. Samples from all patients were detected independently. Total RNA was extracted from endometrial samples. Methylaldehyde degeneration gel electrophoresis was performed to further confirm RNA integrity. Low molecular weight RNA was isolated using the PEG solution precipitation method, according to a previous protocol [13]. The T4 RNA ligase labeling method was adopted according to the Thomson protocol [14]. Microarrays were scanned with a confocal Lux-

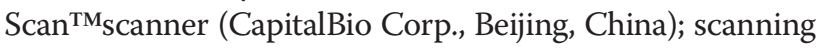
settings were adjusted to obtain a visualized balanced of U6 and tRNA signals across arrays. Data were extracted from the TIFF images using LuxScan ${ }^{\mathrm{TM}} 3.0$ software (CapitalBio Corp.). The microarray intensity data were analyzed by using Significance Analysis of Microarrays (SAM) software. Two class unpaired $t$-tests were performed to identify miRNA expressed differences among the three groups. Genes possessing a q-value equal to 0 and a fold-change $>2$ were considered significantly different.

\section{Messenger RNA profiling with microarray analysis}

Messenger RNA was analyzed from samples in parallel with the miRNA extraction procedures (see Methods section above). A total of 21,522 well-substantiated human mRNA genes were analyzed using the $22 \mathrm{~K}$ Human Genome Array (CapitalBio Corp.). Two $\mu$ g of total RNA was reverse-transcribed, and then double-stranded cDNAs (containing the T7 RNA polymerase promoter sequence) were synthesized using the CbcScript reverse transcriptase with cDNA synthesis system, according to the manufacturer's protocol (Capitalbio) with the T7 oligo (dT). 
To determine gene products with a significant change in levels of expression, statistical comparisons were done using the two classes unpaired t-tests in SAM software in order to identify the functional classes (gene ontology) of selected genes.

\section{Real-time PCR}

To verify the array results, 3 samples per group were chosen. Real-time PCR reactions were performed using miRNA and mRNA specific primers for miRNA-451 (miR451), the lowest expression of miRNA, Spp1, and Ang expression. The GenBank accession numbers of each gene, along with the primer sequences and PCR product sizes of the amplified fragment are listed in Table 1. Five mg of total RNA extracted from each sample was digested with RNase-free DNase I (Promega, San Luis Obispo, CA USA) and reverse-transcribed into cDNA using Superscript II reverse transcriptase (Invitrogen, Carlsbad, CA USA). mRNA of the housekeeping gene $A C T B$ (forward primer: AAGTACTCCGTGTGGATCGG; and reverse primer: ACATCTGCTGGAAGGTGGAC) was used as an endogenous control. Duplicate samples of the target and reference genes were amplified in separate wells; controls without the RT step were included for each primer pair to check for any contaminants. Melting (dissociation) curves of PCR reactions were monitored to ensure a single PCR product and no primer dimmer. All experiments were repeated 40 cycles. The relative expression ratio of a target gene was calculated based upon efficiency and the CT deviation of an unknown sample versus the control (using myometrium cDNA as a calibrator); this was expressed in comparison to a reference gene [15]. The mean CT ratios were expressed as fold differences in gene expression compared with myometrium (gene expression $=1$ ).

\section{Immunohistochemistry methods}

After deparaffinizing sections, the section slides were rehydrated in steps with distilled water $(\mathrm{dH} 2 \mathrm{O})$; slides were immersed in $0.5 \% \mathrm{v} / \mathrm{v}$ hydrogen peroxide/methanol for 10 minutes. The antigen retrieval protocol can be carried out at this time, should this procedure be deemed necessary. Tissue sections were washed in $\mathrm{dH}_{2} \mathrm{O}$ twice (5 minutes each), then blocked with blocking solution (biotinylated goat anti-rabbit immunoglobulin G). Tissue sections were quickly labeled with a PAP pen before the tissue sections dried. After blocking, primary antiserum diluted in blocking solution (1:100 dilution; Santa Cruz Biotechnology, Inc., Santa Cruz, CA, USA) was added and incubated overnight at $4^{\circ} \mathrm{C}$. The sections were incubated with biotinylated secondary antibody diluted in blocking reagent for 30 minutes at $25^{\circ} \mathrm{C}$. Finally, $\mathrm{ABCom}-$ plex/HRP was added for 30 minutes at $25^{\circ} \mathrm{C}$; sections were developed with 3, 3' diaminobenzidine tetrahydrochloride (DAB) and subsequently counterstained with haematoxylin. The primary antibody was omitted to create negative controls.

The immunostaining was scored semi-quantitatively in each section. The staining intensity and positive percentage were performed independently by two observers ( $\mathrm{Li} \mathrm{R}$ and $\mathrm{Li} \mathrm{L}$ ), and the mean value was obtained. A staining score was calculated as follows: $\mathrm{H}$-score $=\Sigma \mathrm{Pi}$ $(\mathrm{i}+1)$, where $\Sigma \mathrm{Pi}$ is the sum of $\mathrm{Pi}, \mathrm{Pi}=$ positive cells $/ 100$ calculated cells $\times 100 \%$, and $\mathrm{i}=$ intensity score (negative $=0$, weak $=1$, moderate $=2$, strong $=3$ ). This score value could vary between 0 and 400 .

\section{Statistical analysis}

Intensity values were analyzed using the SAM method, which is a statistical technique for finding significant genes in a set of microarray experiments [16]. Two class unpaired $\mathrm{t}$-tests were performed to identify mRNA differences among the three groups. Genes possessing a q-value equal to 0 and a fold-change $>2$ were considered significantly different. The q-value is the false discovery rate, which measures how significant the gene is. The Statistics Package for Social Sciences (SPSS) 13.0 software (SPSS Inc., Chicago, IL, USA) was used to analyze the data by Student's $t$-test and rank test. A $P<0.05$ was considered statistically significant.

\section{Pathway analysis}

In order to identify gene expression, the relationship between biologic context and pathways was analyzed using commercially available software (Ingenuity Systems, Redwood City, CA, USA). Ingenuity pathway analysis was performed on mRNA genes expressed in the endometrium, comparing normal and elevated $\mathrm{P}$ groups; this was to predict mRNA target genes of differentially

Table 1 The GenBank accession numbers of the primers and sequences and sizes of the amplified fragments used for real-time PCR analysis

\begin{tabular}{|c|c|c|c|c|}
\hline Gene & GenBank accession no. & Sequence $\left(5^{\prime}-3^{\prime}\right)$ & Length & Amplicon size (bp) \\
\hline $\operatorname{miR}-451$ & hsa-miR-451 & $\begin{array}{l}\text { RT:GTCGTATCCAGTGCAGGGTCCGAGGTATTCGCACTGGATACGACaactca } \\
\text { AS: GCGAAACCGTTACCATTACTGA }\end{array}$ & & \\
\hline Spp1 & NM_000582 & $\begin{array}{l}\text { R:TGGGGTCTACAACCAGCATA } \\
\text { F:ACATCTITGCGTITCTACCG }\end{array}$ & $\begin{array}{l}20 \\
20\end{array}$ & 103 \\
\hline Ang & NM_001145 & $\begin{array}{l}\text { R:CTGTGGTTGGCATCATAGTG } \\
\text { F:CATGTACGTTGCTATCCAGGC }\end{array}$ & $\begin{array}{l}21 \\
21\end{array}$ & 264 \\
\hline
\end{tabular}


expressed miRNA. A p-value $<0.05$ was used to determine the statistical significance.

\section{Results}

The relationship between miRNA and the target mRNA in endometrial receptivity was determined to assist in the determination of the molecular pathways that affect receptivity between higher and normal P levels.

\section{miRNA microarray screening}

A total of 4 down-regulated miRNAs demonstrated statistically significant differential expression between the control, normal P, and elevated P groups (fold change $<0.2$ ); this implies that four miRNAs exhibited a relative decreased expression (hsa-miR-451, hsa-miR-424, hsa$m i R-125 b$, and $h s a-m i R-30 b$; Figure 1 and Table 2).

\section{mRNA microarray screening}

Total endometrial RNA from five samples per group was extracted by dilation and curettage. These RNA preparations were then used to probe the human gene
Table 2 Relative expression of miRNAs decreased in endometrial samples taken during the implantation window between the groups, as shown by miRNA microarray analysis

\begin{tabular}{lll}
\hline Fold change & $\boldsymbol{q}$ value $(\%)$ & HUGO name \\
\hline 0.123 & 0 & hsa-miR-451 \\
0.135 & 0 & hsa-miR-424 \\
0.185 & 0 & hsa-miR-125b \\
0.186 & 0 & hsa-miR-30b \\
\hline
\end{tabular}

microarray comprised of 21,522 genes. Only those genes with a $q$ value $<5 \%$ in the one class method from SAM analysis and a ratio of at least 2-fold difference among the groups, were considered. A total of 22 genes displayed significant $(P<0.05)$ decreases in expression from endometrial samples taken during the implantation window between the groups. Among the 22 mRNA genes, 13 up-regulated and 9 down-regulated were detected in the elevated P group (Figure 2 and Table 3). In an effort to further explore the biologic relationship between reduced
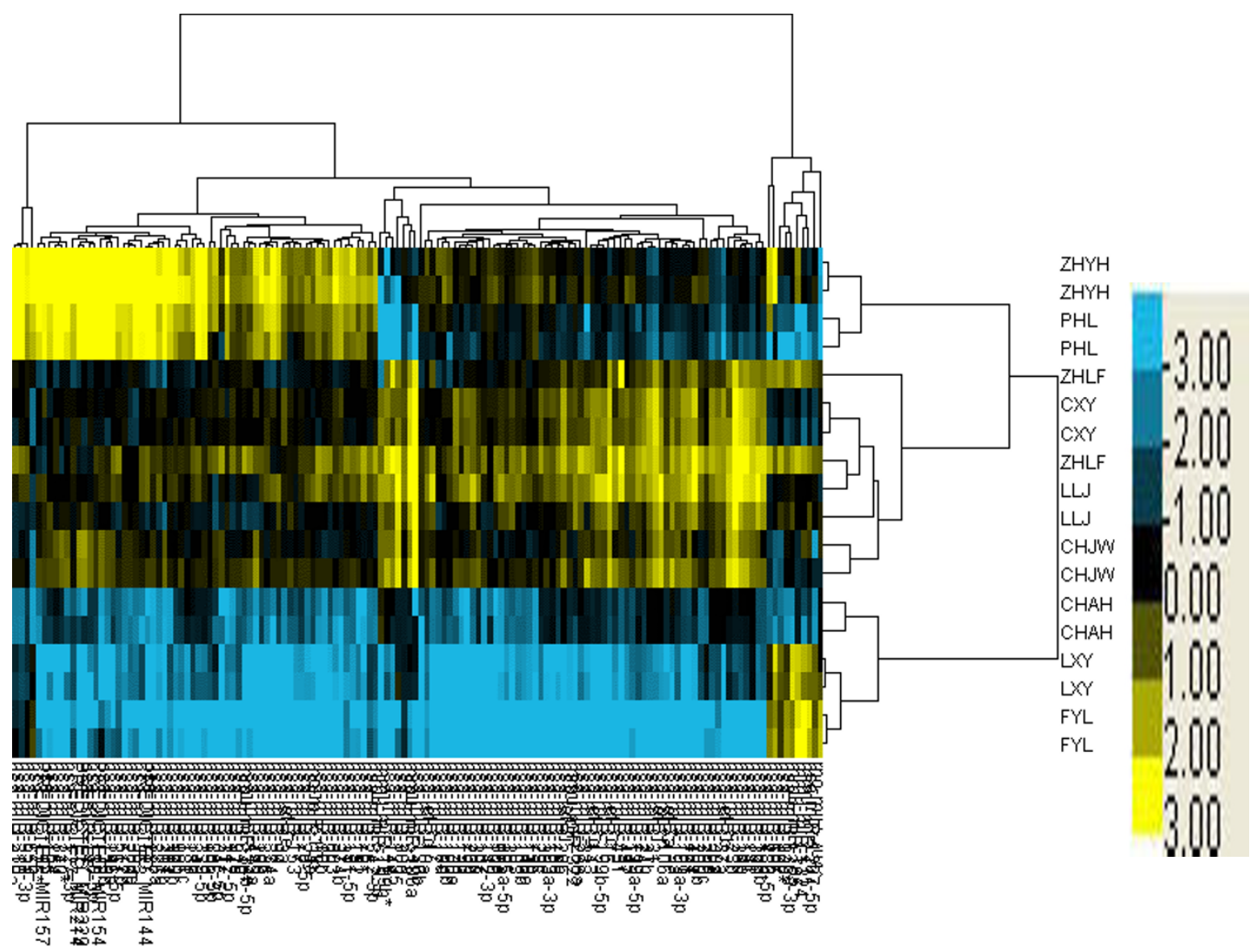

Figure 1 Four down-regulated miRNAs possessing significant differential expression between normal progesterone and elevated progesterone groups (fold change $<0.2$ ) 


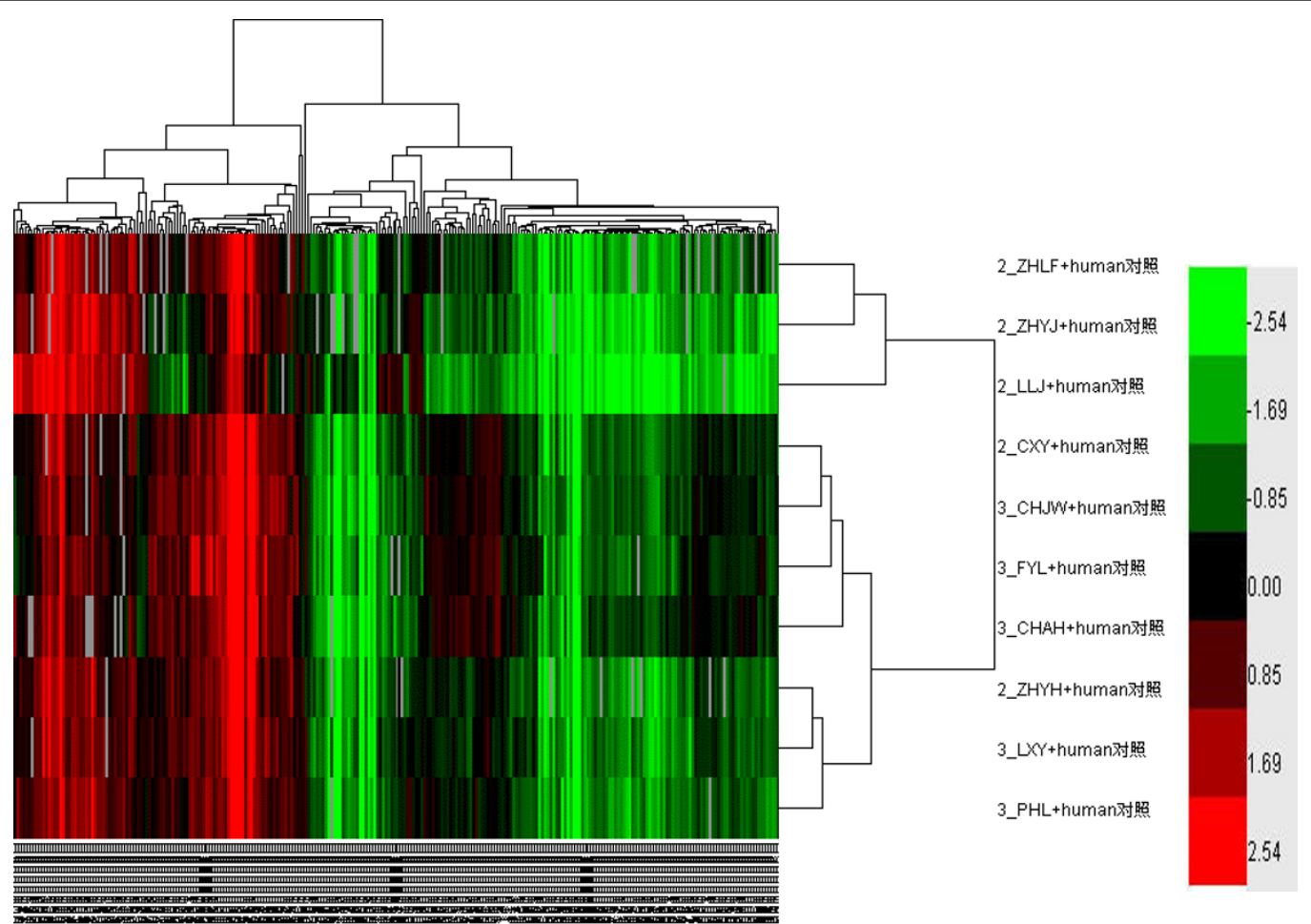

Figure 2 Thirteen up-regulated and 9 down-regulated genes between normal and elevated progesterone groups (fold change $>2$ upregulated and $<0.5$ down-regulated).

Table 3 Relative expression of mRNAs decreased in endometrial samples taken during the implantation window between normal and elevated progesterone groups, as shown by mRNA microarray analysis

\begin{tabular}{|c|c|c|c|c|}
\hline $\begin{array}{l}\text { Fold } \\
\text { change }\end{array}$ & $q$ value $(\%)$ & Description & $\begin{array}{l}\text { HUGO } \\
\text { name }\end{array}$ & GenBank accession no. \\
\hline 2.7119 & 13.1050 & Serine-protein kinase ATM & Atm & NM_000051,NM_138292 \\
\hline 2.6390 & 5.7126 & Proteinase activated receptor 1 precursor (PAR-1) & $F 2 r$ & NM_001992 \\
\hline 2.5389 & 9.0200 & Osteopontin precursor (Bone sialoprotein 1) & Spp1 & NM_000582 \\
\hline 2.5156 & 5.7126 & SA hypertension-associated homolog isoform 1 & Sah & NM_202000,NM_005622 \\
\hline 2.4192 & 13.1050 & Lysozyme C precursor & Lyz & NM_000239 \\
\hline 2.3716 & 9.0200 & Kinetochore associated 2 & Kntc2 & NM_006101 \\
\hline 2.1913 & 5.7126 & Liver carboxylesterase 1 precursor & Ces3 & NM_001266 \\
\hline 2.1760 & 9.0200 & $\mathrm{~N}$-acetylgalactosamine kinase & Galk2 & NM_001001556,NM_002044 \\
\hline 2.1591 & 13.1050 & Alcohol dehydrogenase; Fe-containing alcohol dehydrogenase 1 & Adhfel & NM_144650 \\
\hline 2.1208 & 13.1050 & Heterogeneous nuclear ribonucleoproteins A2/B1 & Hnrpa2b1 & NM_002137,NM_031243 \\
\hline 2.0778 & 5.7126 & Influenza virus NS1A binding protein; NS1-binding protein & Ivns1abp & NM_016389,NM_006469 \\
\hline 2.0611 & 13.1050 & Lactamase, beta 2 & Lactb2 & NM_016027 \\
\hline 2.0439 & 9.0200 & Ubiquitin carboxyl-terminal hydrolase 16 & Usp16 & NM_006447,NM_001001992 \\
\hline 0.4958 & 35.2491 & Histone deacetylase 5 (HD5) & Hdac5 & NM_005474,NM_139205 \\
\hline 0.4796 & 32.6148 & 1-acyl-sn-glycerol-3-phosphate acyltransferase beta & Agpat2 & NM_006412 \\
\hline 0.4305 & 5.1933 & Angiogenin precursor & Ang & NM_001145 \\
\hline 0.4253 & 32.6148 & LAG1 longevity assurance homolog 4 & Lass4 & NM_024552 \\
\hline 0.4141 & 35.2491 & Fibrinogen beta chain precursor & Fgb & NM_005141 \\
\hline 0.4102 & 32.6148 & $\begin{array}{l}\text { Similar to lymphocyte antigen } 6 \text { Complex, locus G5B; G5b protein; open } \\
\text { reading frame } 31\end{array}$ & Np_660282 & NM_145239 \\
\hline 0.3214 & 32.6148 & Left-right determination factor B precursor & Leftb & NM_020997 \\
\hline 0.2476 & 32.6148 & $\begin{array}{l}\text { WNT1 inducible signaling pathway protein } 2 \text { precursor (WISP-2), } \\
\text { (Connective tissue growth factor-like protein) (CTGF-L), (Connective tissue } \\
\text { growth factor-related protein 58) }\end{array}$ & Wisp2 & NM_003881 \\
\hline 0.1734 & 35.2491 & Tyrosinase precursor & Tyr & NM_000372 \\
\hline
\end{tabular}


receptivity and identified miRNA, a search of the Sanger Database for predicting mRNA targets of the miR-451 (the most differentially expressed, fold change $=0.12$ ) was conducted. The Sanger Database-predicted mRNA gene targets of $m i R-451$ were then cross-referenced against the 22 mRNA genes; indeed, it was shown that $m i R-451$ gene targets were differentially expressed between normal and elevated $\mathrm{P}$ endometrium genes from the Affymetrix microarray expression analysis. Four of 22 (18\%) differentially expressed genes, Tyr (tyrosinase precursor), Usp16 (ubiquitin carboxyl-terminal hydrolase 16), Galk2 (N-acetylgalactosamine kinase), and Spp1 (osteopontin precursor) were also predicted mRNA targets of $m i R-451$.

\section{Real-time PCR}

In an effort to validate the array expression findings, one of the four differentially-expressed miRNAs (hsa-miR451) was chosen for real-time PCR (RT-PCR) analysis (Figure 3); three samples were taken per group. The expressions proved to be lower in group 2 (34.3\%, $47.4 \%$, and $39.9 \%$; average, $40.56 \%)$ than in group $1(44.43 \%$, $100 \%$, and $82.85 \%$; average, $75.76 \%$ ). Two of the 22 differentially-expressed mRNA (Spp1 and Ang) were chosen for RT-PCR analysis (Figure 3). Spp1 was one of the 4 miR-451 regulated genes. We also chose 3 samples per group for RT-PCR analysis. Spp1 expression was higher (group 1: $12.12 \%, 26.65 \%$, and $57.89 \%$; average, $32.22 \%$ vs. group 2: $40.21 \%, 42.90 \%$, and $44.17 \%$; average, 42.43\%), while Ang expression was the lower (group 1: $80.68 \%, 78.34 \%$, and $30.05 \%$; average, $63.03 \%$ vs. group 2 , $37.36 \%, 87.60 \%$, and $55.38 \%$; average, $60.11 \%$ ). These results totally supported the accuracy of the mRNA microarray analysis.

\section{Protein verification}

In order to explore the biological significance of the Spp 1 and Ang genes, their expression in normal and elevated $\mathrm{P}$ endometrium were analyzed by imunohistochemistry methods. The results demonstrate that osteopontin and vascular endothelial growth factor (VEGF) proteins were found in both normal and elevated P endometrial tissues, both stromal and glandular cells. The osteopontin was staining more intense and VEGF less intense in women with high versus normal serum $P$ group, as calculated by the $\mathrm{H}$-score (Figure 4 and Table 4).

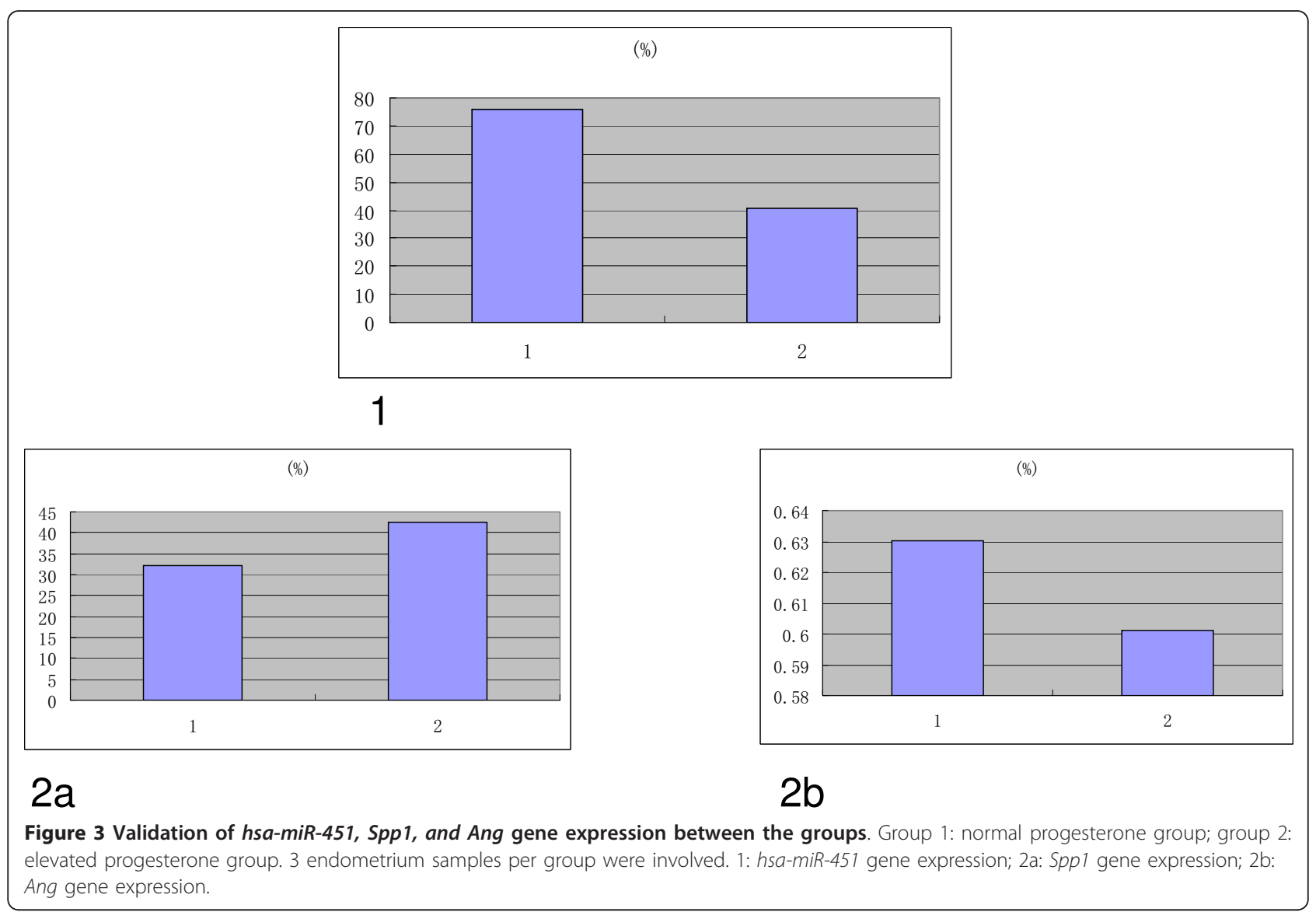




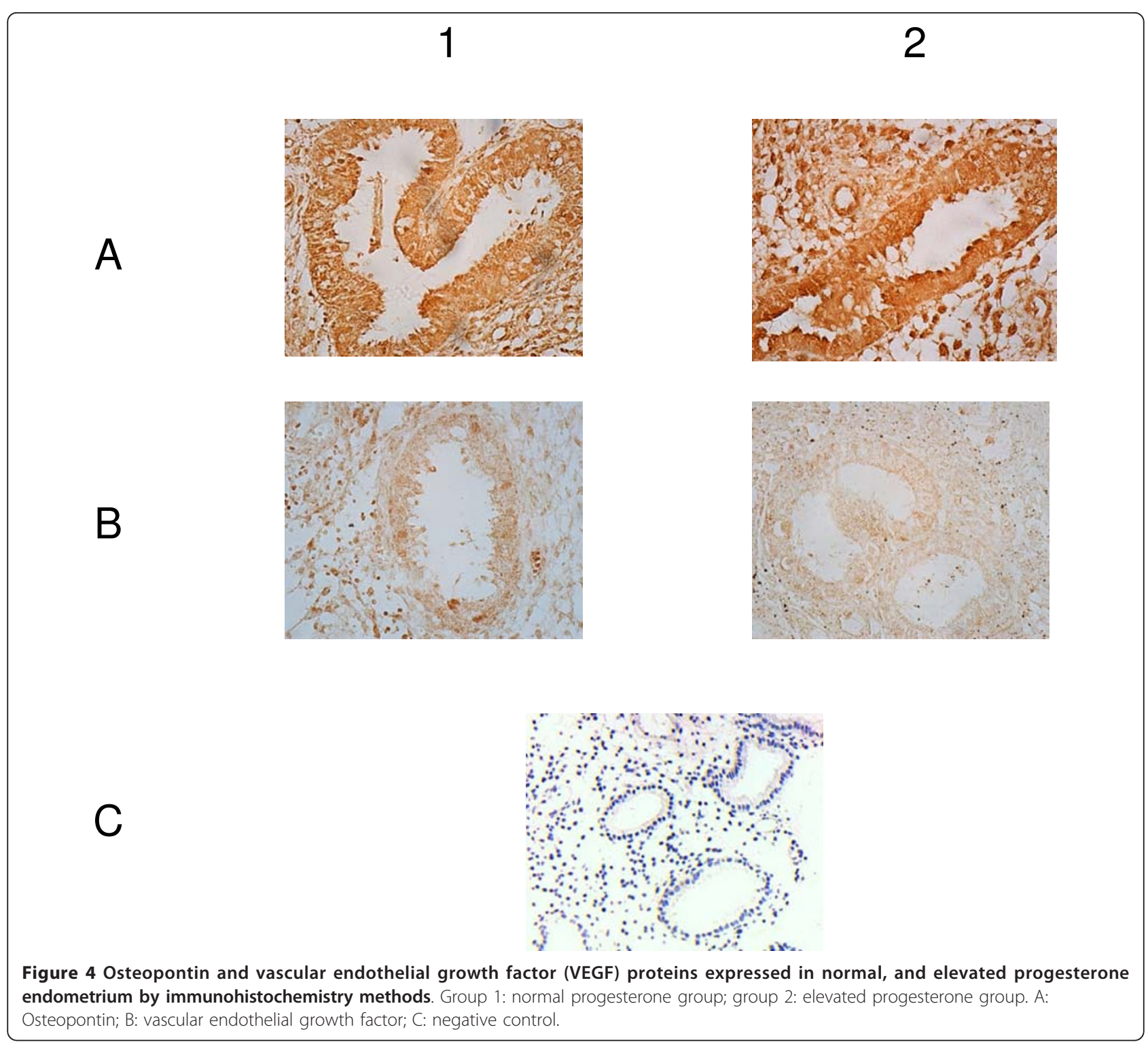

\section{Discussion}

Successful implantation of embryos is an important physiologic event in the establishment of pregnancy [17]. High serum P concentrations could have an adverse effect on endometrial conditions, a pattern observed through our clinical research [4]. However,

Table 4 Different expression of OPN and VEGF in endometrial samples taken during the implantation window between normal and elevated progesterone groups, as shown by imunohistochemistry analysis

\begin{tabular}{lllll}
\hline & Group 1 & Group 2 & $\boldsymbol{t}$ & $\boldsymbol{P}$ \\
\hline Samples & 7 & 12 & & \\
OPN & $313 \pm 29$ & $362 \pm 19$ & -4.036 & 0.003 \\
VEGF & $343 \pm 34$ & $304 \pm 28$ & 2.683 & 0.016 \\
\hline
\end{tabular}

what factors affect endometrial receptivity of high $\mathrm{P}$ patients? Global gene expression analysis has been used to search the etiologic factors of many diseases [18]. In recent years, many studies have been conducted to explore the cause of endometrial receptivity reduction [19]. Our study used a gene array to investigate the expression of differential genes in the endometrium in patients with elevated P; this was chosen because of the extremely poor outcome in IVF-ET treatment observed in these individuals. Some of the 22 genes identified proved to be involved in invasive growth and the cystoskeleton; among them, a number have been previously reported to affect endometrial receptivity directly or indirectly, including oesteopontin [20] and angiogenin (which regulates VEGF expression) [21]. 
We have utilized genome-wide analysis to identify a series of miRNA which may contribute to reductions in endometrial receptivity. By executing a parallel analysis of mRNA levels in a subset of these samples, we have identified a panel of mRNAs that may influence endometrial receptivity. A proportion of these mRNA genes have been previously reported as predicted targets of the miRNA [22]. Using the Sanger miRNA database, several of the differentially-expressed genes have been identified as target genes for miRNA in this study, which may play an important role in reducing endometrial receptivity. Furthermore, we have identified 4 miRNAs and 22 mRNA genes that were differentially-expressed between normal and elevated P endometrium. Using the Sanger database, 4 of the 22 mRNA genes were identified as predicted targets of the miRNA-451; several of these mRNA genes are associated with endometrial receptivity.

The relationship between miRNA gene expression and the mRNA targets is very complicated. It is believed that miRNA influences cell function via post-transcriptional modulation [23]; thus, the effect of miRNA is largely directed toward post-transcriptional activity. The post-transcriptional down-stream effects of miRNA on translation may operate on a feedback-loop, with consequences impacting mRNA transcription of the miRNA predicted targets. Moreover, the effect of miRNA on messenger RNA degradation may also result in changes in mRNA levels that may be detected through an array expression analysis.

Osteopontin is an important factor because of its involvement in the implantation process. This glycoprotein is a ligand for $\alpha \mathrm{v} \beta 3$ integrin; osteopontin mediates cellular adhesion and migration during embryo implantation and is regulated by $\mathrm{P}$. Its maximal expression in endometrial epithelial cells has been observed during the window of implantation [24]. VEGF and its receptor had intense expression in the endometrial epithelial cells of the implantation widow and also showed stromal immunoreactivities by the time that secondary villi differentiate into tertiary villi [25]. When there were some abnormal expressions of cytokines, such as OPN and VEGF, the endometrial receptivity decreased, which led to poor pregnancy rate in IVF patients. A better pregnant outcome in frozen ET cycles may be achieved when the patient has an elevated $\mathrm{P}$ following the administration of hCG.

\section{Conclusions}

We performed a gene pathway analysis on miRNA and mRNAs in order to report the effects of this differential expression between normal and elevated P. This pathway analysis identified osteopontin and angiogenin to play an important role in endometrial receptivity of elevated P. All this data may provide a reason to explain the reduced pregnancy rate in patients with elevated $\mathrm{P}$, thus creating new markers for improved treatment for patients undergoing IVF-ET with elevated P levels.

\section{Acknowledgements}

This research was supported by Mega-projects of Science Research for the 11th Five-year Plan, grant number 2007BAI04B04, and National Basic Research Program of Chinam, 973 Program 2007CB511901. Thanks to Professor Huai L. Feng and Mr. Dennis Marchesi for their revision of the manuscript.

\section{Author details}

'Peking University Third Hospital, No. 49, North Huayuan Road, Haidian District, Beijing 100191, PR China. ${ }^{2}$ Institute of Population Research, Peking University, No.5 Yiheyuan Road Haidian District, Beijing 100871, PR China.

\section{Authors' contributions}

$\mathrm{RL}$ carried out the operation, participated in the sequence data collection and analysis and drafted the manuscript. JQ instigated the study, and participated in its design and coordination and helped to draft the manuscript. Both authors read and approved the final draft.

\section{Competing interests}

The authors declare that they have no competing interests.

Received: 27 November 2010 Accepted: 6 March 2011 Published: 6 March 2011

\section{References}

1. Ubaldi F, Camus M, Smitz J, Bennink HC, Van Steirteghem A, Devroey P: Premature luteinization in vitro fertilization cycles using gonadotropinreleasing hormone agonist (GnRH-a) and recombinant folliclestimulating hormone (FSH) and GnRH-a and urinary FSH. Fertil Steril 1996, 66:275-280.

2. Shulman A, Ghetler $Y$, Beyth Y, Ben-Nun I: The significance of an early (premature) rise of plasma progesterone in in vitro fertilization cycles induced by a 'long protocol' of gonadotropin releasing hormone analogue and human menopausal gonadotropins. J Assist Reprod Genet 1996, 13:207-211.

3. Melo MAB, Meseguer M, Garrido N, Bosch E, Pellicer A, Remohí J: The significance of premature luteinization in an oocyte-donation programme. Hum Reprod 2006, 21:1503-1507.

4. Li R, Qiao J, Wang L, Zhen X, Lu Y: Serum progesterone concentration on day of hCG administration and IVF outcome. Reprod Biomed Online 2008, 16:627-631.

5. Aplin J: Embryo implantation: the molecular mechanism remains elusive. Reprod Biomed Online 2006, 13:833-839.

6. Navot D, Bergh PA, Williams M, Garrisi GJ, Guzman I, Sandler B, Fox J, Schreiner-Engel P, Hofmann GE, Grunfeld L: An insight into early reproductive processes through the in vivo model of ovum donation. $J$ Clin Endocrinol Metab 1991, 72:408-414.

7. Fazleabas A, Donnelly KM, Srinivasan S, Fortman JD, Miller JB: Modulation of the baboon (Papio anubis) uterine endometrium by chorionic gonadotrophin during the period of uterine receptivity. Proc Natl Acad Sci USA 1999, 96:2543-2548.

8. Giudice LC: Potential biochemical markers of uterine receptivity. Hum Reprod 1999, 14:3-16.

9. Varghese AC, Goldberg E, Bhattacharyya AK, Agarwal A: Emerging technologies for the molecular study of infertility, and potential clinical applications. Reprod Biomed Online 2007, 15:451-456.

10. Hoozemans DA, Schats R, Lambalk CB, Homburg R, Hompes PG: Human embryo implantation: current knowledge and clinical implications in assisted reproductive technology. Reprod Biomed Online 2004, 9:692-715.

11. Giudice $L C$, Telles $T L$, Lobo $S$, Kao $L$ : The molecular basis for implantation failure in endometriosis, on the road to discovery. Ann N Y Acad Sci 2002, 955:252-264.

12. Carson DD, Lagow E, Thathiah A, Al-Shami R, Farach-Carson MC, Vernon M, Yuan $L$, Fritz MA, Lessey B: Changes in gene expression during the early to mid-luteal (receptive phase) transition in human endometrium 
detected by high-density microarray screening. Mol Hum Reprod 2002, 8:871-879.

13. Watanabe T, Takeda A, Mise K, Okuno T, Suzuki T, Minami N, Imai H: Stagespecific expression of microRNAs during Xenopus development. FEBS Lett 2005, 579:318-324.

14. Thomson M, Parker J, Perou CM, Hammond SM: A custom microarray platform was analyzed of miRNA gene expression. Nature Methods 2004 1:47-53.

15. Pfaffl MW: A new mathematical model for relative quantification in realtime RT-PCR. Nucleic Acids Res 2001, 29:e45.

16. Tusher $V$, Tibshirani R, Chu G: Significance analysis of microarrays applied to transcriptional responses to ionizing radiation. Proc Natl Acad Sci USA 2001, 98:5116-5121.

17. Salamonsen LA: Role of proteases in implantation. Rev Reprod 1999, 4:11-22.

18. Aghajanova L, Hamilton AE, GiudiceS LC: Uterine receptivity to human embryonic implantation: Histology, biomarkers, and transcriptomics. Semin in Cell \& Develop Biol 2008, 19:204-211.

19. Nikas G, Develioglu OH, Toner JP, Jones HW Jr: Endometrial pinopodes indicate a shift in the window of receptivity in IVF cycles. Hum Reprod 1999, 14:787-792.

20. Fujimoto J, Ichigo S, Hori M, Tamaya T: Alteration of E-cadherin, alphaand beta-catenin mRNA expression in human uterine endometrium during the menstrual cycle. Gynecol Endocrinol 1996, 10:187-191.

21. Chen Y, Zhang YL, Zhang QY: Gene expression and regulation of blastocyst formation. Develop Reproduct Biol 2002, 11:75-81.

22. Doench JG, Sharp PA: Specifidity of microRNA target selection in translational repression. Genes Dev 2004, 18:504-511.

23. Sontheimer EJ, Carthew R: Silence from within: endogenous siRNAs and miRNAs. Cell 2005, 122:9-12.

24. Talbi S, Hamilton AE, Vo KC, Tulac S, Overgaard MT, Dosiou C, Le Shay N, Nezhat CN, Kempson R, Lessey BA, Nayak NR, Giudice LC: Molecular phenotyping of human endometrium distinguishes menstrual cycle phases and underlying biological processes in normo-ovulatory women. Endocrinology 2006, 147:1097-1121.

25. Kaufmanna P, Mayhewb TM, Charnock-Jonesc DS: Aspects of Human Fetoplacental Vasculogenesis and Angiogenesis. II. Changes During Normal Pregnancy. Placenta 2004, 25:114-126.

doi:10.1186/1477-7827-9-29

Cite this article as: Li et al: MicroRNA array and microarray evaluation of endometrial receptivity in patients with high serum progesterone levels on the day of hCG administration. Reproductive Biology and Endocrinology 2011 9:29.

\section{Submit your next manuscript to BioMed Central and take full advantage of:}

- Convenient online submission

- Thorough peer review

- No space constraints or color figure charges

- Immediate publication on acceptance

- Inclusion in PubMed, CAS, Scopus and Google Scholar

- Research which is freely available for redistribution 